\title{
Variation in the Origin of Superior Cerebellar Artery: A Case Report
}

\author{
Authors \\ Pratibha Shakya $^{1}$, Bismay Das $^{2}$, Neelesh Kumar Shakya ${ }^{3}$, Chhandamayee Mohanty ${ }^{4}$ \\ ${ }^{1,4}$ Department of Anatomy, Institute of Medical Sciences, Banaras Hindu University, Varanasi \\ ${ }^{2}$ Department of Pathology, Fr Mullar Medical College, Mangalore \\ ${ }^{3}$ Department of Forensic Medicine and Toxicology, Institute of Medical Sciences, Banaras Hindu \\ University, Varanasi \\ Corresponding Author \\ Dr Pratibha Shakya
}

Junior Resident, Department of Anatomy, Institute of Medical Sciences, Banaras Hindu University,

Varanasi-221005(U.P)

Email: shakya_pratibha@rediffmail.com Phone No: 91-8533869264

\begin{abstract}
-
Introduction-The superior cerebellar artery is a branch of basilar artery and arises just before its bifurcation into posterior cerebral arteries. A bilateral origin of superior cerebellar artery from posterior cerebral artery is very rarely reported in literature. This variation is significant for surgeons who are dealing with pathology in this area.

Case Report- Present study was conducted in Department of Anatomy, IMS, BHU, Varanasi. Microsurgical dissection was performed on the arteries of Circle of Willis. The origin of superior cerebellar artery was observed in 12 adult cadavers. In one case, bilateral origin of superior cerebellar artery was observed from posterior cerebral artery instead of basilar artery. The other brain vessels had no anomalies in the origin of their branches on either side.

Conclusion- Knowledge of variation of Circle of Willis is very important because injury to occulomotor, trochlear, trigeminal nerves present in this area may cause neurological manifestations. This variation can be explained by the embryological development in this region.
\end{abstract}

Key Words- Variation, Origin, Superior cerebellar artery.

\section{Introduction-}

Superior cerebellar artery arises from distal part of basilar artery, just before bifurcation into posterior cerebral arteries. Superior cerebellar artery passes laterally below the occulomotor nerve, which separate it from posterior cerebral artery. Superior cerebellar artery supplies superior cerebellar surface, pons, superior medullary velum, tela choroidea of third ventricle. and pineal body.
Bilateral origin of the Superior cerebellar artery from the posterior cerebral artery is very rarely reported. Origin of the Superior cerebellar artery from the posterior cerebral artery can compress occulomotor nerve, trochlear nerve and trigeminal nerve which may lead to neurological manifestations. Variations of superior cerebellar artery have recently become significant because of magnetic resonance imaging and computed tomography. Other variations of superior 
cerebellar artery reported are congenital absence of superior cerebellar artery, duplication, triplication, tortuous course and fenestration. In present case, bilateral origin of superior cerebellar artery from basilar artery is reported which can be understood on embryological basis.

\section{Case Report-}

Present study was conducted on 12 cadavers of adult age group (25-60 years) of Indian ethnicty in Department of Anatomy, Institution of Medical Sciences, Banaras Hindu University. After removal of brain, fine dissection was done to observe any variation in Circle of Willis .
In one case, bilateral origin of superior cerebellar artery from posterior cerebral artery was found. Right and left superior cerebellar artery originated from posterolateral aspect of posterior cerebral artery at $5 \mathrm{~mm}$ and $2 \mathrm{~mm}$ distance from the rostral end of basilar artery. After origin from posterior cerebral artery, right and left cerebellar arteries took lateral course and divided into medial and lateral branches. Outer diameters of the right and left posterior cerebral arteries were 4 and $5 \mathrm{~mm}$ respectively. At origin, outer diameter of the superior cerebellar arteries was $3 \mathrm{~mm}$. Outer diameter of basilar artery was $6.5 \mathrm{~mm}$. Origin of basilar artery was at pontomedullary sulcus.

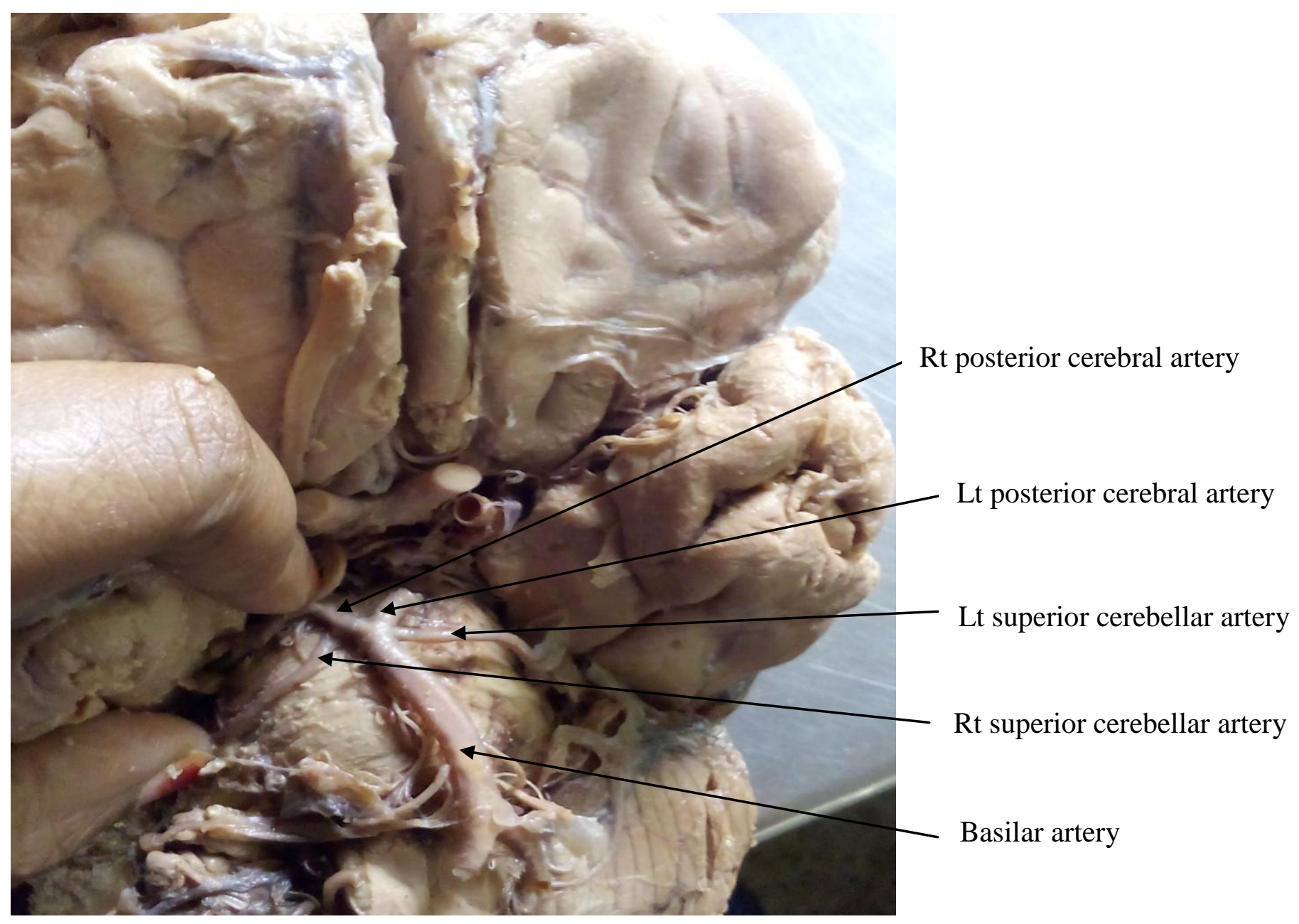

Figure 1- Diagram showing bilateral origin of superior cerebellar artery from posterior cerebral artery.

\section{Discussion-}

Various authors described variations of superior cerebellar artery. Duplication of superior cerebellar artery was found $28 \%, 20 \%, 14 \%$,
$5.9 \%, 25 \%$ by Padget et $\mathrm{al}^{1}$ (1948), Salamon et $\mathrm{al}^{2}$ (1976), Hardy et $\mathrm{al}^{3}$ (1980), Uchino et $\mathrm{al}^{4}$ (2003), Dagcinar et $\mathrm{al}^{5}$ (2007) respectively. Triplication was also found in $8 \%$ and $2 \%$ by Mani et $\mathrm{al}^{6}$ 
(1968) and Hardy et $\mathrm{al}^{3}$ (1980). Origin of the superior cerebellar artery from the posterior cerebral artery was found in $4 \%$ and $2.6 \%$ of cases by Hardy et $\mathrm{al}^{3}$ (1980), Uchino et $\mathrm{al}^{4}$ (2003), but a bilateral occurrence of this variation is extremely rare (Caruso et $\mathrm{al}^{7}, 1991$ ).

Variation in present case report can be understood on embryological basis. Basilar artery is formed by the fusion of two longitudinal neural arteries. Lack of normal fusion at the rostral end of basilar artery at the origin of the superior cerebellar artery leads to origin of superior cerebellar artery from posterior cerebral artery. Thus, the origin of the superior cerebellar artery from the posterior cerebral artery on both side is most probably associated with the unusual development of the distal basillary region during embryogenesis.

\section{Conclusion-}

Radiologists should know the variation of Circle of Willis to avoid misinterpretation of the radiological images. Preoperative identification of variations of superior cerebellar artery is important for interventional procedures of the distal basilar artery. Knowledge of the anatomy of Circle of Willis with its variations is very useful for clinicians for surgical planning because surgery may cause more risks and complications in this region due to presence of important vascular and neural structures.

\section{References-}

1. Padget DH. The development of the cranial arteries in the human embryo. Contrib Embryol 1948; 32: 205-261.

2. Salamon G, Huang YP. Radiologic anatomy of the brain. Berlin Springer Verlag 1976; 305-306.

3. Hardy DG, Peace DA, Rhoton AL., Jr Microsurgical anatomy of the superior cerebellar artery. Neurosurgery 1980; 6: 10-28.

4. Uchino A, Sawada A, Takase Y, Kudo S. Variations of the superior cerebellar artery: MR angiographic demonstration. Radiat Med 2003; 21: 235-238.
5. Dagcinar A, Kaya AH, Aydın ME, Kopuz C, Senel A, Demir MT, Corumlu U, Celik F, Sam B. The superior cerebellar artery: anatomic study with review. Neurosurg Q 2007; 17: 235-240.

6. Mani RL, Newton TH, Glickman MG. The superior cerebellar artery: an anatomicroentgenographic correlation. Radiology 1968; 91: 1102-1108.

7. Caruso G, Vincentelli F, Rabehanta P, Giudicelli G, Grisoli F. Anomalies of the P1 segment of the posterior cerebral artery: early bifurcation or duplication, fenestration, common trunk with the superior cerebellar artery. Acta Neurochir (Wien) 1991; 109: 66-71. 